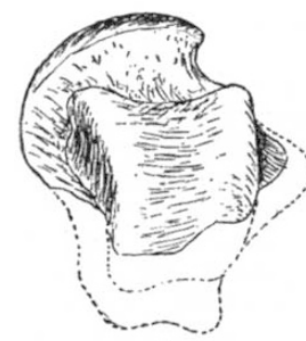

A
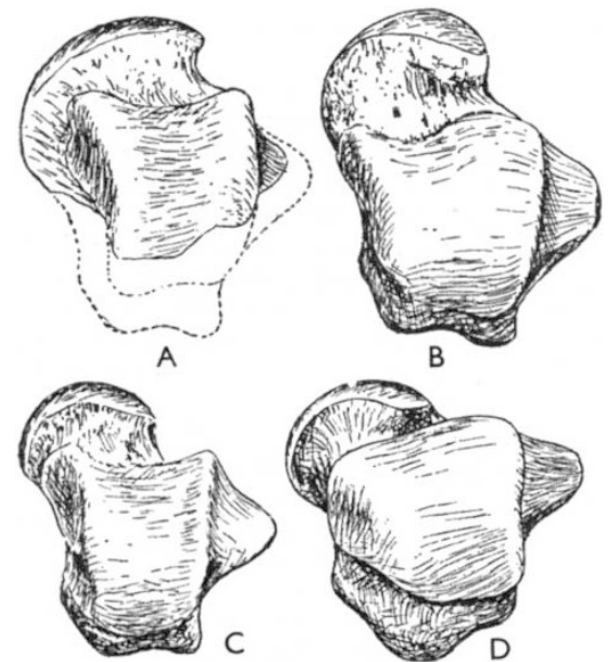

B

Right talus (astragulus) of (A) Paranthropus robustus Broom; Right talus (astragulus) of (A) chimpanzee ; $(D)$ a large gorilla. $A, B$, and $C$ are nat. size ; $D$ is $\frac{1}{2}$ nat. size.

perfect, and rather more than the upper half of the distal end is satisfactorily preserved.

In size, this talus agrees fairly well with that of a female Bushman; but in structure the bone differs considerably. The articular surface for the navicular is much broader and more horizontal than in the Bushman, and it extends a little farther inwards than in most human tali.

The articular surface for the tibia and fibula is narrower than in any human tali I can find, and a little differently shaped. A comparison with the proximal articular surface in the talus of the chimpanzee shows considerable resemblance, but the articulation for the navicular in the chimpanzee is very different.

There is very little resemblance between the talus of Paranthropus and that of the gorilla; the tibial articulation being very different.

There cannot, I think, be the slightest doubt that this talus is that of the type Paranthropus robustus. The head, jaw, humerus and ulna fragments, the bones of the hand, and this talus are all from one mass of bone breccia less than a cubic foot in size.

The talus is manifestly that of a Primate slightly larger than a chimpanzee. In general structure the bone resembles that of a man more than it does that of any of the living anthropoids, and the little evidence that it brings is in favour of Paranthropus having been bipedal, and of its having had a well-developed hallux.

Paranthropus, though a little less human in its milk molars than Australopithecus or Plesianthropus, is more human in its having a much larger brain.

Paranthropus, in having a brain of about 650 c.c. and a very lightly built body of probably not more than $80 \mathrm{lb}$. or $90 \mathrm{lb}$., and in being most probably bipedal, with delicate slender hands, must have been an animal much more like a human being than either the chimpanzee or gorilla. Like the other known Australopithecines, it was certainly not a forestliving Primate, but a being who lived among the rocks and on the plains and hills as the baboons do to-day.

It is hoped that before long a complete work will be issued on all that is known of the Taungs, the Sterkfontein and the Kromdraai ape-men.

Transvaal Museum,

R. Broom.

\section{Distribution of Colour-blind Men in Great Britain}

DurIng the past two years the colour vision of many thousands of recruits for the Royal Navy has been tested by a modified form of the Ishihara and Stilling Tests. Thus for the first time it has become possible to compare the proportions of colour-blind men in different regions of Great Britain on a large scale. Significantly greater proportions have been found to occur in the western than in the eastern half of the country. The following table gives the percentages of defectives in nine major areas of Britain, each percentage being based on more than 6,000 cases. Each percentage has also been adjusted for the lower level of intelligence which occurs in some testing centres than in other centres, since it has been found that men of very low intelligence tend to do less well at the test.

$$
\text { Area }
$$

N.E. Scotland (Wick, Edinburgh, Gaiashiels, etc.)

London and S.E. (including chatham, Aldershot and Brighton)

East Coast (Newcastle down to East Anglia) Industrial North Central (Chesterfield, Derby, Nottingham, Leeds, Northamp-

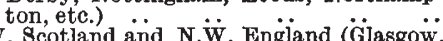

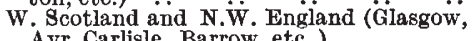
Ayr, Carlisle, Barrow, etc.) Industrial N.W. (Stoke, Liverpooi, Man-

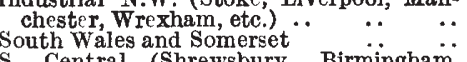
S. Centra] (Shrewsbury, Birmingham, Hereford, oxford, Reading, etc.) S.W. England (Portsmouth, Salisbury,

$\begin{array}{cc}\begin{array}{c}\% \\ \text { Defective }\end{array} & \begin{array}{c}\text { Corrected } \\ \text { for } \\ \text { intelligence }\end{array} \\ 5 \cdot 37 & 5 \cdot 00 \\ 6 \cdot 81 & 6 \cdot 69 \\ 6.99 & 6 \cdot 65 \\ 7 \cdot 43 & 7 \cdot 31 \\ 7 \cdot 72 & 7 \cdot 31 \\ 7 \cdot 72 & 7 \cdot 41 \\ 7 \cdot 76 & 7 \cdot 41 \\ 8.86 & 8 \cdot 65 \\ 9 \cdot 45 & 9.21\end{array}$

Analysis of variance shows that differences between areas are statistically significant, when compared with variations within areas. The $F$-ratio is 6.19 with 8 and 70 degrees of freedom; a ratio of $3 \cdot 8$ would have a probability of 0.001 .

The figures suggest that colour defect may be racially connected with pigmentation, since it is generally accepted that light hair and eyes are more prevalent in the north and east, dark colouring in the south and west of Great Britain. While not possible in war-time, we hope later to be able to compare our results in detail with figures for the geographical distribution of blonde versus brunette characters.

It should be noted that the total percentage for all areas of 7.49 per cent is much higher than the usual estimate of about 4 per cent for males, simply because the test employed is a difficult one which picks out many of the colour-weak, or anomalous trichromats, as well as the strictly colour-blind.

P. E. Vernon.

National Institute of Industrial

A. Straker. Psychology,

Aldwych House, Aldwych,

London, W:C.2. Nov. 9.

\section{Instability of Stilbamidine in Aqueous Solution}

THE changes which stilbamidine and related com. pounds undergo in solution on exposure to the action of light have received considerable attention in the last two years, and several publications dealing with the subject have appeared in the literature, from which it seems that the methods of approach have been biological and physical rather than chemical. Fulton and Yorke', Fulton ${ }^{2}$, Barber, Slack and Wien? 